\title{
MANAGEMENT OF CUT-THROAT INJURIES- OUR EXPERIENCES
}

\author{
Prathap Kumar Kukkapalli1, S. Khalilulla ${ }^{2}$
}

${ }^{1}$ Senior Resident, Department of ENT, Apollo Institute of Medical Sciences (AIMSR), Chittoor, Andhra Pradesh. ${ }^{2}$ Assistant Professor, Department of ENT, Apollo Institute of Medical Sciences (AIMSR), Chittoor, Andhra Pradesh. ABSTRACT

\section{BACKGROUND}

Cut-throat injuries of the neck are one of the emergencies encountered in the emergency department. Neck contains multiple vital structures with little anatomic protection from overlying bone, muscle and soft tissue. These injuries may be suicidal, homicidal or accidental. Familial troubles, psychiatric illness and poverty are the triggering factors in suicidal attempts. Motives of homicide include political conflict, sex related crimes, familial/land disputes etc. The cut injury in suicidal cases is not so deep, whereas it may involve vital structures in homicidal injuries. The management and prognosis differ in injuries of different areas of neck. Expeditious decision-making often is required. Compounding difficulties in evaluation and management is the result of complicated anatomy of the neck.

Aims and Objectives- To study the nature of injury, mean period of hospital stay, treatment outcomes and prognosis of cut-throat injuries.

\section{MATERIALS AND METHODS}

This is a case series conducted from $1^{\text {st }}$ July 2016 to $31^{\text {st }}$ January 2018, who had cut-throat injuries. The patients coming to the emergency department were selected, examined and managed.

\section{RESULTS}

Cut-throat injuries commonly involve adults of $3^{\text {rd }}$ and $4^{\text {th }}$ decade. In our study of 18 patients, 14 were males and 4 were females with male: female ratio being 3.5: 1 . Among 18 patients of cut-throat injuries majority of them were homicidal (7) followed by suicidal (6) and then accidental (5). Cut-throat injuries most often involve zone-II, i.e. from lower border of cricoid to angle of mandible, as it is the most accessible part of the neck. In our study zone-II injuries dominated with $83 \%$ followed by zone-I with $11 \%$ and zone-III by $6 \%$.

\section{CONCLUSION}

Cut-throat injuries may show various degrees of severity, nevertheless, no cervical trauma should be underestimated in spite of minimal trauma. Surgical exploration is invariably the preferred treatment in our experience. Diagnostic work-up of neck injuries is difficult in most of the cases and is dependent on vital signs, neurological status and location of the wound. Tracheostomy should be done prior to exploration and repair of laryngeal injuries.

\section{KEYWORDS}

Larynx, Trachea, Neck, Homicidal, Suicidal, Tracheostomy etc.

HOW TO CITE THIS ARTICLE: Kukkapalli PK, Khalilulla S. Management of cut-throat injuries- our experiences. J. Evolution Med. Dent. Sci. 2018;7(17):2141-2143, DOI: 10.14260/jemds/2018/479

\section{BACKGROUND}

The neck contains multiple vital structures with little anatomic protection from overlying bone, muscle and soft tissue. Cut-throat injuries may be Suicidal, Homicidal or Accidental. It is essential to obtain early definitive control of the airway as a top priority in all the patients with neck injuries followed by vascular and aerodigestive tract assessment.

In analysing wounds based on craniocaudal direction, the neck is divided into three horizontal zones by Monson.

'Financial or Other Competing Interest': None.

Submission 12-03-2018, Peer Review 08-04-2018,

Acceptance 14-04-2018, Published 23-04-2018.

Corresponding Author:

Dr. Prathap Kumar Kukkapalli,

H. No. 23-8-63, Flat No. 207,

Hindu Towers, Royal Nagar,

R. C. Road, Opp. Water Tank,

Tirupathi-517501, Andhra Pradesh.

E-mail: prathapdr97@yahoo.co.in

DOI: $10.14260 /$ jemds $/ 2018 / 479$

\section{(c) $(1) \ominus$}

\section{Zone-I}

It extends from the clavicle to the cricoid cartilage and includes the thoracic inlet. Injuries in this zone carry high mortality.

\section{Zone-II}

It extends from cricoid cartilage to the angle of mandible. Injuries to this region are usually clinically apparent.

\section{Zone-III}

It is the area extending from the angle of mandible to the base of the skull.

One school of thought favours mandatory surgical exploration for all penetrating injuries, (Bishara RA, Pasch AR, Douglas DD et al) ${ }^{1}$ and the other favours selective exploration based on results of angiography, oesophagoscopy and oesophagography (Ateberry LR, Dennis JW et al). ${ }^{2}$

Injuries to the airway are clinically overt with bubbling and air movement through the wound. Penetration of thyrohyoid membrane causes bleeding into paraglottic space and thus causing airway obstruction and penetration of cricothyroid membrane cause surgical emphysema. Fiberoptic laryngoscopy in the stable patient is an essential element of physical examination. CT scans offer better visualisation of subglottic and anterior commissure areas 
(Gussac GS, Jurkowich GJ, Luterman A et al). ${ }^{3}$ It is essential to obtain early definitive control of airway as a top priority in all patients with major neck injuries. Intubation in this setting is hazardous; may cause iatrogenic injury i.e. false passages as a result of already precarious airway (Cherian TA, Rupa V, Raman $\mathrm{R}$ et al),4 so many authors strongly recommend tracheostomy rather than intubation (Schaefer SD, Ainsworth JZ et al). ${ }^{5}$ The optimal timing for surgical management is to repair primarily than relying on healing by secondary intention or grafting. Lacerations are meticulously approximated with 4-0 or 5-0 absorbable suture material. Mildly displaced simple fractures can be repaired with nonabsorbable sutures through outer perichondrium. And displaced fractures of laryngeal cartilages are reduced and immobilised with titanium miniplates preferably (Woo P et al). ${ }^{6}$ Stents are indicated for two weeks (Schaefer SD) ${ }^{5}$ for anterior commissure and extensive soft tissue injury, which provide stability and prevent mucosal adhesions.

Major cervical vascular injury may present as vigorous external bleeding or cervical haematoma. Carotids are best exposed through a standard cervical incision along anterior border of sternocleidomastoid. The injured internal or common carotid artery can be repaired using standard vascular surgery techniques (Ascansio JA, Valenziano CP, Dennis JW, Menawal SS et al). ${ }^{7}$

The oesophagus must be sufficiently mobilised to allow full evaluation. The injury should usually be repaired primarily by one-layer or two-layer technique. Injuries of the pharynx above the constrictor muscles do not seem as critical as injuries of oesophagus and are repaired primarily whenever practical and kept nil orally for 6 - 7 days.

As there are many important nerves that run through neck, it is important to document full neurological examination. In most of trauma cases, primary repair of neural injuries is impractical. Even with careful microscopic repair of transected nerve, vocal cord mobility is not regained due to mixture of abductor and adductor fibres in the nerve (Gordan JH, McCabe BF et al). ${ }^{8}$

\section{Objective}

To study the nature of injury, mean period of hospital stay, treatment outcomes and prognosis of cut-throat injuries.

\section{MATERIALS AND METHODS}

This is a case series conducted by Department of ENT, AIMSR, Chittoor from $1^{\text {st }}$ July 2016 to $31^{\text {st }}$ January 2018 for a period of 1 year 7 months. The study involved 18 cases of cut-throat injuries from the emergency department. Consent for the study was taken from the ethics committee.

\section{Inclusion Criteria}

Patients of both the sex with any age group coming to the emergency department without any intracranial injuries and cervical bone fractures are included in the study.

\section{RESULTS}

These observations and results are based on study of 18 patients presented with cut-throat injuries to emergency department and managed by Department of ENT and Head and Neck Surgery at Apollo Institute of Medical Sciences, Chittoor during last 1 year 7 months, i.e. between July 2016 and January 2018.

\begin{tabular}{|c|c|c|c|c|c|c|}
\hline $\begin{array}{c}\text { Age } \\
\text { (yrs.) }\end{array}$ & $0-10$ & $11-20$ & $21-30$ & $31-40$ & $41-50$ & $51-60$ \\
\hline No. & 1 & 1 & 5 & 8 & 1 & 2 \\
\hline \multicolumn{7}{|c|}{ Age Incidence of Cut-Throat Injuries } \\
\hline
\end{tabular}

Cut-throat injuries commonly involve adults of $3^{\text {rd }}$ and $4^{\text {th }}$ decade. In our series, lowest age of incidence is $7 \mathrm{yrs}$. and highest is 55 yrs.

\begin{tabular}{|c|c|}
\hline Males & Females \\
\hline 14 & 04 \\
\hline \multicolumn{2}{|c|}{ Sex Incidence of Cut-Throat Injuries } \\
\hline
\end{tabular}

In many studies, cut-throat injuries most often involve males in ratio of $3: 1$. In our study of 18 patients, 14 were males and 4 were females with male: female ratio being 3.5:1.

\begin{tabular}{|c|c|}
\hline Accidental & 5 \\
\hline Homicidal & 7 \\
\hline Suicidal & 6 \\
\hline Pattern of Injury \\
\hline
\end{tabular}

Among 18 patients in our study, majority of them were homicidal (7) followed by suicidal (6) and then accidental (5).

\begin{tabular}{|c|c|}
\hline Zone & No. of Cases \\
\hline I & 02 \\
\hline II & 15 \\
\hline III & 01 \\
\hline \multicolumn{2}{|c|}{ Involvement of Different Zones } \\
\hline
\end{tabular}

Cut-throat injuries most often involve zone-II, as it is the most accessible part of the neck. In our study too zone-II injuries dominated with $83 \%$ followed by zone-I with $11 \%$ which is followed by zone-III with $6 \%$.

\begin{tabular}{|c|c|}
\hline Name of Structure & No. of Cases \\
\hline Larynx & 05 \\
\hline Trachea & 00 \\
\hline Vascular & 01 \\
\hline Spinal cord & 00 \\
\hline Oesophagus & 00 \\
\hline Soft tissue only & 12 \\
\hline \multicolumn{2}{|c|}{ Structures Involved } \\
\hline
\end{tabular}

In our study most of the cases, i.e. 12 only the soft tissue of the neck is involved. Laryngeal injuries are noted in 5 cases and facial vessels in one case. In none of the cases trachea, spinal cord or oesophagus are involved.

\begin{tabular}{|c|c|}
\hline Tracheostomy & No. of Cases \\
\hline Done & 04 \\
\hline Not done & 15 \\
\hline \multicolumn{2}{|c|}{ Airway Management (Tracheostomy) } \\
\hline
\end{tabular}

As a basic principle tracheostomy is necessary in cases with laryngotracheal injuries. In our study, tracheostomy done in 4 cases among 5 cases with laryngeal injuries and remaining 1 case is managed conservatively due to minimal airway injury. 


\begin{tabular}{|c|c|}
\hline Complication & No. of Cases \\
\hline Post-op wound infection & 02 \\
\hline Laryngotracheal stenosis & 00 \\
\hline Tracheo-oesophageal fistula & 01 \\
\hline Vocal cord paralysis & 00 \\
\hline \multicolumn{2}{|c|}{ Complications } \\
\hline
\end{tabular}

In our study among 18 cases, complications are seen in 3 of the cases. In 2 cases post-operative wound infection is seen which subsided with secondary suturing and antibiotics and tracheo-oesophageal fistula in 1 case.

Mortality in our study, only one patient died due to sudden abdominal haemorrhage on second post-operative day and mortality rate is $5.5 \%$.

\section{DISCUSSION}

This study includes 18 patients. Many of the studies show male dominance, our study too shows same results. Most of the cases we managed were presented to Emergency department.

These injuries may be suicidal/ homicidal/ accidental. In present study $33.33 \%(n=6)$ of cases were suicidal, $38.88 \%$ $(n=7)$ were homicidal and $27.7 \%(n=5)$ accidental. Most of the homicidal cases are due to personal conflicts and illegal affairs, road traffic accidents are responsible for majority of the accidental cases, whereas the patients with suicidal injuries had history of psychiatric illness or psychologically compromised.

In a study conducted at University of Mantiba, the location of injuries was zone-I 11\%; zone-II $85 \%$ and zone-III $4 \%$ (Nason RW, Burns CM et al). ${ }^{9}$ In our study too it was more or less equal zone-I $11 \%$, zone-II $83 \%$ and zone-III $6 \%$.

Controversy exists regarding best way to establish an alternate airway in the presence of laryngeal trauma. But many authors like Schafer, ${ }^{5}$ who have done extensive studies on penetrating neck trauma strongly recommend tracheostomy rather than intubation in victims of laryngeal trauma who require alternate airway. Optimally, tracheostomy for laryngeal injury should be performed at $4^{\text {th }}$ or $5^{\text {th }}$ ring of trachea. In our study, tracheostomy done in 4 among 5 cases with laryngeal injury.

Cartilaginous framework injuries of the larynx are meticulously approximated with 4-0 or 5-0 non-absorbable suture materials along with tracheostomy. If possible, knots should be placed outside laryngeal lumen to prevent formation of granulation tissue. In the present study, we have 1 among the 18 cases with minimal displaced fracture which is repaired with 3-0 Mersilk. Displaced fractures of laryngeal cartilages are reduced and immobilised with titanium miniplates preferably (Woo P et al). ${ }^{6}$ Unfortunately, we did not get any case with displaced fractures.

In managing oesophageal injuries, the oesophagus must be sufficiently mobilised to allow full evaluation of the wound and careful debridement of devitalised tissue usually be repaired primarily. Pharyngeal injuries are treated with debridement and primary closure whenever possible. The patient is kept on nil by mouth for 7 days.

In case of neural injuries, primary repair is impracticable. Even with careful microscopic repair of transected nerve, vocal cord mobility is not regained due to mixture of abductor and adductor fibres in the nerve (Gordan $\mathrm{JH}$, McCabe BF et al). ${ }^{8}$
In the postoperative period despite strict adherence to proper principles of management, we have encountered with complications like wound gaping, secondary infection of the wound.

\section{CONCLUSION}

Cut-throat injuries are becoming one of the major injuries involving the head and neck region day by day. Cut-throat injuries may show various degrees of severity, nevertheless no cervical trauma should be underestimated in spite of minimal trauma. Surgical exploration is invariably the preferred treatment in our experience.

Cut-throat injuries most often involve the male sex in the ratio of 3.5: 1. Cut-throat injuries most often involve zone-II, as it is the most accessible part of the neck. Diagnostic workup of neck injuries is difficult in most of the cases and is dependent on vital signs, neurological status and location of the wound. Computed tomography in stable patients with cut injuries appears to be safe.

Cut-throat injuries of zone-II in asymptomatic patients is associated with low mortality and morbidity than other two zones. A selective management protocol with investigations directed by symptoms is most appropriate approach for such patients. Tracheostomy should be done prior to exploration and repair of laryngeal injuries. In patients with minimal airway injuries tracheostomy is not mandatory and can be managed by simple repair and patient should be kept on Ryle's tube feeding for one week.

\section{REFERENCES}

[1] Bishara RA, Pasch AR, Douglas DD, et al. The necessity of mandatory exploration of penetrating Zone II neck injuries. Annals of Surgery 1986;100(4):665-60.

[2] Ateberry LR, Dennis JW, Menawat SS, et al. Physical examination alone is safe and accurate for evaluation of vascular injuries in penetrating Zone II neck trauma. Journal of American College of Surgery 1994;179(6):657-62.

[3] Gussac GS, Jurkowich GJ, Luterman A. Laryngeal trauma - an update. Annals of Otolaryngology 1998;75: p. 1103.

[4] Cherian TA, Raman VRR. External laryngeal trauma: analysis of 30 cases. Journal of Laryngology and Otology 1993;107:920-3.

[5] Schaefer SD. Primary management of laryngeal trauma. Annals of Otol Rhinol Laryngology 1982;91(4 Pt 1):399-402.

[6] Woo P. Laryngeal framework reconstruction with miniplates. Annals of Otol Rhinol Laryngology 1990;99(10 Pt 1):772-7.

[7] Asensio JA, Valenziano CP, Falcone RE, et al. Management of penetrating neck injuries: the controversy surrounding Zone II injuries. Surgical Clinics of North America 1991;71(2):267-96.

[8] Gordan JH, McCabe BF. The effect of accurate neurorraphy on reinnervation and return of laryngeal function. Laryngoscope 1968;78(2):236-50.

[9] Nason RW, Assuras GN, Gray PR, et al. Penetrting neck injuries: analysis of experience from a Cannadian trauma centre. Canadian Journal of Surgery 2001;44(2):122-6. 